(2) Open Access Full Text Article

REVIEW

\title{
Intraoperative Optical Coherence Tomography Guided Ocular Surgeries: Critical Analysis of Clinical Role and Future Perspectives
}

This article was published in the following Dove Press journal: Clinical Ophthalmology

\section{Amar Pujari iD* \\ Divya Agarwal* \\ Rohan Chawla \\ Atul Kumar \\ Namrata Sharma (iD \\ Dr. Rajendra Prasad Centre for Ophthalmic Sciences, All India Institute of Medical Sciences, New Delhi, India \\ *These authors contributed equally to this work}

\begin{abstract}
Intraoperative imaging of ocular tissues for diagnostic and therapeutic applications has gained immense admiration in recent years. The real time cross-sectional imaging, as well as three and four dimensional reconstruction abilities of intraoperative optical coherence tomography (iOCT), has enhanced our knowledge on many fronts in surgical maneuvers. In this review, we discuss the iOCT discovered constructive knowledge in the cornea, cataract, refractive, glaucoma, pediatric ocular, and various retinal conditions. The practical utility with decision modifying aspects along the specified ocular tissues and with respect to specific ocular entities have been narrated. Moreover, limitations and future directions have also been emphasized to make ophthalmic care more comprehensive in the future.
\end{abstract}

Keywords: intraoperative optical coherence tomography, iOCT, hand-held optical coherence tomography and intraoperative microscope integrated optical coherence tomography

\section{Introduction}

Innovations in ocular imaging are on the rise at a very rapid pace since the description of optical coherence tomography (OCT) in 1991. ${ }^{1}$ Initial description of outpatient based anterior and posterior segment imaging has now moved on to real time intraoperative imaging. These milestones are the result of continuous constructive efforts by the clinicians and innovators. Intraoperative optical coherence tomography I(iOCT) began with the handheld imaging to reach the existing microscope integrated platform. In addition, rather than just two-dimensional real time assessment, unwavering endeavors to reconstruct the volumetric three- and four-dimensional images are also on the rise.

To date, several studies have tested the utility of iOCT under a variety of circumstances, in addition, timely reviews and expert opinions have also enriched our knowledge on iOCT. ${ }^{2-12}$ However, a comprehensive review to summarize the pan ophthalmic utility from a clinicians perspective is still lacking, therefore, this comprehensive review was undertaken to analyze the utility of iOCT. Here, we discuss the anterior segment, posterior segment as well as other utilities in a systematic manner.

\section{Methods}

A systematic English literature search was conducted on PubMed Medline, Web of science, and Scopus using the key words, intraoperative optical coherence tomography,
Correspondence: Amar Pujari

Dr. Rajendra Prasad Centre for

Ophthalmic Sciences, All India Institute of

Medical Sciences, New Delhi, India

Tel +9l 8447226221

Email dramarpujari@gmail.com 
hand-held optical coherence tomography, and intraoperative microscope integrated optical coherence tomography. Till April 2020, original articles, reports, and communications describing the potential clinical use of iOCT in various sections of ophthalmology were included. Articles and reports describing theoretical concepts with little clinical relevance were excluded. A total of 118 articles satisfied our criteria's, following this each article was assessed in detail to enumerate the comprehensive clinical role. The diverse applications were summarized in a systematic and all-inclusive manner from anterior to posterior segment and extraocular indications. At the end, conclusions were mentioned with observed limitations and relevant future directions to overcome the same.

\section{Results}

\section{Cornea, Refractive, and Cataract Utility in Corneal Surgeries}

Imaging of the anterior most layers of the ocular tissues are intended to assess their thickness, morphology, associated opacities, and surgical planes. In this particular subsection, the commonly explored utility is while performing deep anterior lamellar keratoplasty (DALK). During this procedure depth detailed surgical maneuvering has been the key for better surgical success, beginning from trephination till the closure of wounds, every step holds its own clinical intricacy, thus, necessitating a real time imaging tool to picturize the actual cross-sectional tissue changes. During trephination, the extent of the corneal tissue penetration and during the cannula placement its depth and path judgment have been greatly influenced by iOCT. ${ }^{13}$ Several observations were of the opinion that, with iOCT in DALK, the plane of canula introduction, its effect on big bubble morphology and subsequent manual dissection, and suture depth sagacity are all well executed. ${ }^{14}$ In addition, the effect of intraocular pressures on the success of big bubble technique, ${ }^{15}$ interface events during surgery, ${ }^{16,17}$ and the added advantage of femtosecond laser in the customization of intraoperative parameters have all provided the inclusive notions for using iOCT. ${ }^{18}$

Under complex clinical scenarios, such as the identification of superficial fibrovascular tissue in severe limbal stem cell deficiency, iOCT helps in the discretion of abnormal tissue from normal, thus preventing excessive resection of healthy tissue. ${ }^{19}$ Similarly, morphological comprehensibility during phototherapeutic keratectomy, ${ }^{20}$ corneal shield ulcer dissection, ${ }^{21}$ corneal biopsy, ${ }^{22}$ corneal injury repair, ${ }^{23}$ and during keratoplasty are all noted to have a positive impact with the iOCT. ${ }^{24}$ Furthermore, these applications can be enhanced by contriving the fourdimensional tissue volumetric images ${ }^{25}$ (Figures 1 and 2).

During posterior corneal surgeries also iOCT becomes a necessary tool to image, as the chronically decompensated cornea often hinders the key anterior chamber details such as air-endothelial reflex and others. Before beginning the surgery, precut DSAEK and pre-stripped DMEK tissue examination helps in the characterization of endothelial texture, Descemet's anatomy, peripheral subtler Descemet's detachments and the level and extent of cut. $^{26}$ Including the PIONEER study it has repeatedly been emphasized by different authors that the intraoperative graft-host interactions, such as the introduction of graft tissue, its orientation, posterior surface of the host tissue, interface fluid area, interface fluid volume and graft

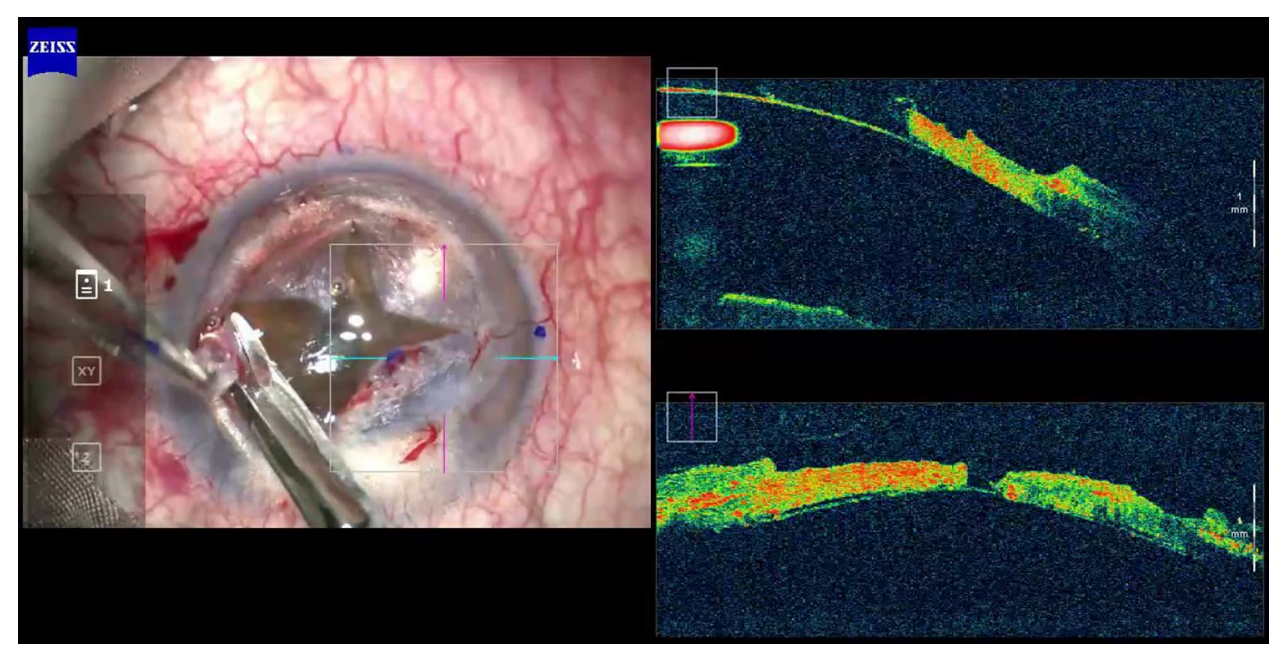

Figure I iOCT guided depth resolved detailed augmentation of air injection procedure with graded tissue dissection during big bubble Deep Anterior Lamellar Keratoplasty. 


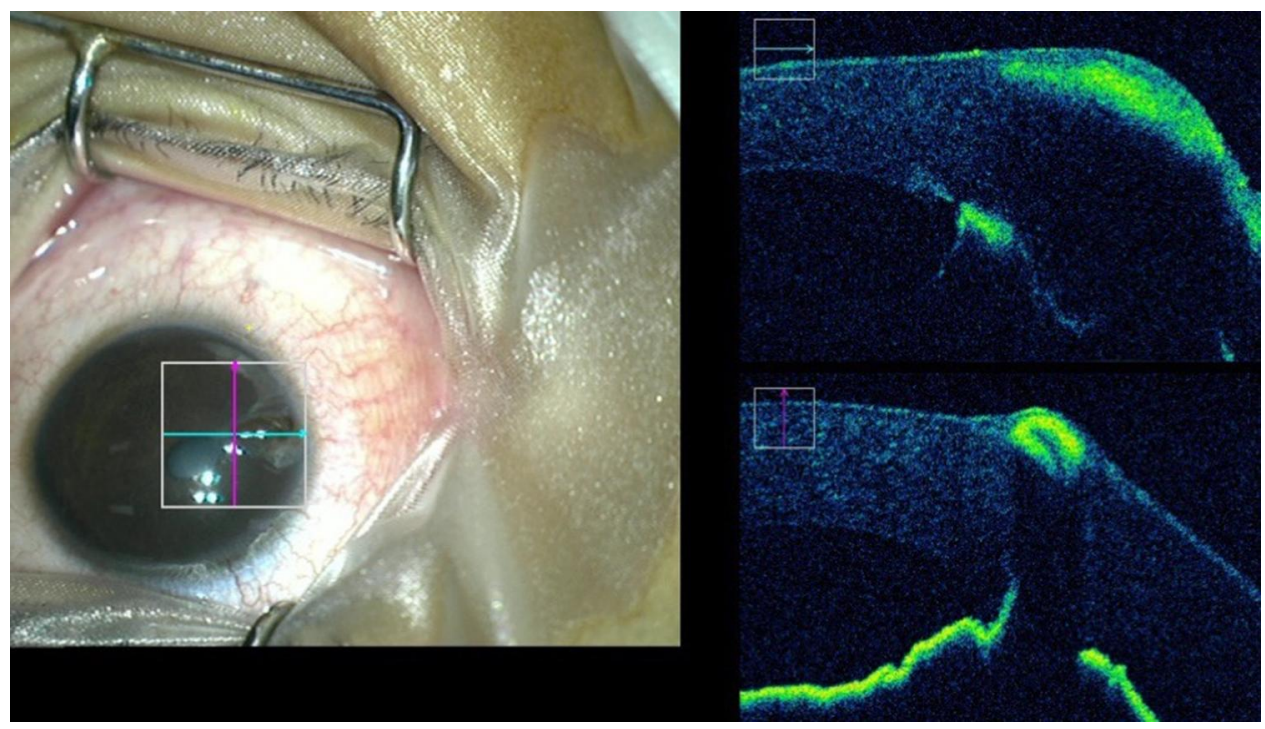

Figure 2 Full thickness corneal perforation with uveal tissue prolapse is better delineated under iOCT. Iris reposition, depth guided suturing and optimal anterior chamber formation in the presence of hazy cornea are well ensured on iOCT.

adherence are all well witnessed and addressed on iOCT. $^{27-29}$

In an observation using iOCT during DSAEK surgery, the combination of positive intracameral pressure coupled with external corneal massage was able to clinch the adhesion of donor lenticule between 1-3 minutes. ${ }^{30}$ While in another observation, the same interface fluid was quantified on a computerized segmentation algorithm and scrutinized the disappearance of the same with iOCT. $^{31}$ The gradual disappearance of fluid can be monitored better with iOCT and if needed venting incisions can be aided till the adherence is achieved. ${ }^{32}$ In complicated cases having fibrous ingrowth along the endothelial and iris with active traction, iOCT will come to the rescue by characterizing the picture prior to Descemet's stripping. ${ }^{33}$

On iOCT, DMEK performing experts were able to successfully localize the peripheral anterior synechiae and residual DM tags under the hazy media. Similarly, DMEK donor tissue preparation, its orientation, and configuration, while injecting into theanterior chamber and contemplation of its complete attachment were evidenced on iOCT. ${ }^{34,35}$ In 100 cases of DMEK, results on iOCT discussed by Patel et al, ${ }^{36}$ revealed the greater advantage for novice surgeons as it reduced the complication and unscrolling time in comparison to senior surgeons. In addition, markings along the graft tissue for orientation were also mitigated. Consequently, the overall agreement tends to uncover constructive advantage of iOCT during all stages of DMEK and DSAEK procedures $^{37,38}$ (Figure 3).

\section{Keratoconus}

In keratoconus eyes, the $\mathrm{BOCT}$ aids in real time computation of corneal thickness at a desired site during the customary CXR procedure. While observing the corneal thickness, Mazotta et $\mathrm{al}^{39}$ witnessed a significant decrease in corneal thickness during the first 10 minutes (a mean reduction of around 80 microns) after corneal soaking. Subsequently, this reduction continued till 30 minutes of imbibition to a total of 90 microns (average). This notion has been registered by other observations on iOCT alone as well as in relation to the speculum. ${ }^{40,41}$

Similarly, during emergencies of acute hydrops with disorganized anatomical layers and obscured details, iOCT enlightens the whereabouts of fluid collection (intrastromal and posterior stromal), quantity, and associated DMDs. Thereafter, it also aids in controlled venting of the fluid with precise suturing and maneuvering along the anterior chamber. ${ }^{42}$ In addition, in eyes with advanced disease, Bowman's membrane transplantation can be reasonably well executed with iOCT. ${ }^{43}$

\section{Refractive Surgery}

In the course of refractive surgery, the iOCT guided observations are sparse and isolated. In an observation during SMILE surgery, the iOCT in real time specified the planes of lenticular dissection from the underlying and overlying stroma, and prevented the creation of false planes with very well set changes along the dissected paths. ${ }^{44}$ Moreover, any encountered difficulties during the 


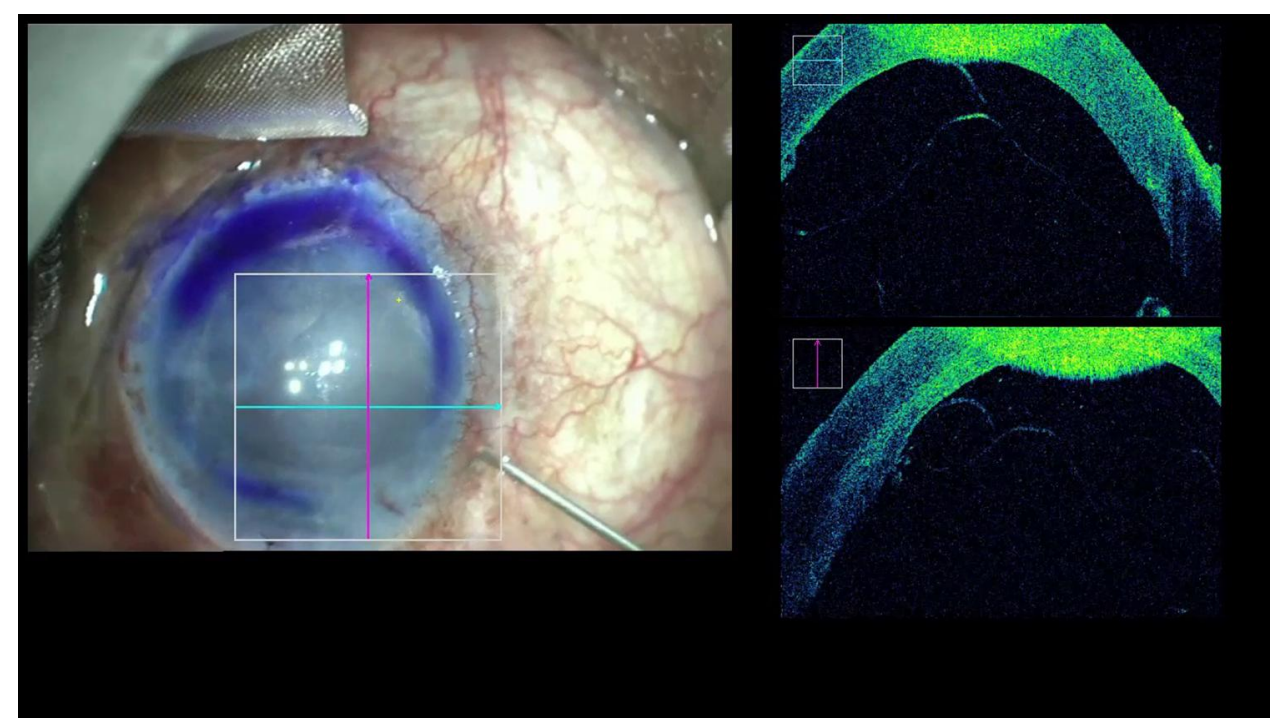

Figure 3 In presence of hazy cornea orientation DMEK scroll can also be better ensured with iOCT.

procedure such as the cap-lenticule adhesion and others can be addressed skillfully if iOCT is within reach, ${ }^{45}$ thus, for inexperienced surgeons and/or learners, SMILE surgery can be more serene with iOCT. Other utilities of iOCT in refractive surgeries are intra-operative real time computation of ICL vaulting to relate the foreseeable vaulting during the post-operative period, the intraoperative and day 1 and day 30 ICL vaulting values have been well correlated in some observations. ${ }^{46,47}$ Similarly, quantification of residual bed thickness during LASIK surgery as an alternative to ultrasound pachymetry has also been explored, however, the risk of underestimation by iOCT still remains. ${ }^{48}$

\section{Cataract and IOL}

As cataract surgery is the most commonly performed ophthalmic surgery, iOCT utilities in here are principally limited to corneal wounds, intraoperative ocular biometry, and intraocular lens related events. At the beginning, iOCT provides cross-sectional details of corneal wounds, such as their direction, gaping, subclinical Descemet's detachment, and hydration resulted changes along stroma. ${ }^{49}$ Whereas during phacoemulsification, the event of nudging of swirling lens fragments onto central endothelium were witnessed and has been found to have significant effect on the endothelial count. ${ }^{50}$ At the end of surgery, IOL apposition with the capsule, that is, full or partial apposition between the central optic and posterior capsule, and, the apposition between the optic edge and posterior capsule were quantified using iOCT. ${ }^{51}$ In an observation, it was noted that only $13 \%$ of the eyes had partial or total optic and capsular apposition, andonly $57 \%$ of eyes had apposition at the edges, therefore, iOCT continues to provide insight into the perspectives which were deemed less important or less explored. ${ }^{51}$ The other often highlighted utility of iOCT is the real time assessment of intraoperative anterior chamber depth. It has been emphasized that the intraoperative distance between the endothelium and the anterior capsule has better predictions for optimal IOL positioning with least postoperative refractive errors ${ }^{52,53}$ (Figures 4 and 5).

\section{Glaucoma Surgery}

Glaucoma surgery often involves the placement of delicate miniature implants into the angle and/or surgeries along the subtler levels of angle structures. ${ }^{54}$ In this array the iOCT provisions a structured visualization of ocular coats, anterior chamber details, Schlemm's canal, and the sutures while titrating canaloplasty. ${ }^{55}$ Furthermore, the scleral depth dissection, positioning of tubes, navigation of the needles/ instruments, trabecular aspiration, and ab interno trabeculotomy have all been validated on real time imaging as well as with three-dimensional customized reconstructions. ${ }^{56-61}$ However, to what extent these procedures possess clinical relevance and how it can be useful for routine applications needs further clarity. In addition, future evaluations are mandated in a larger subset of patients with a special interest on complex eyes, because such evidence has the potential to drive the glaucoma surgery in a more predictable direction in the near future. 


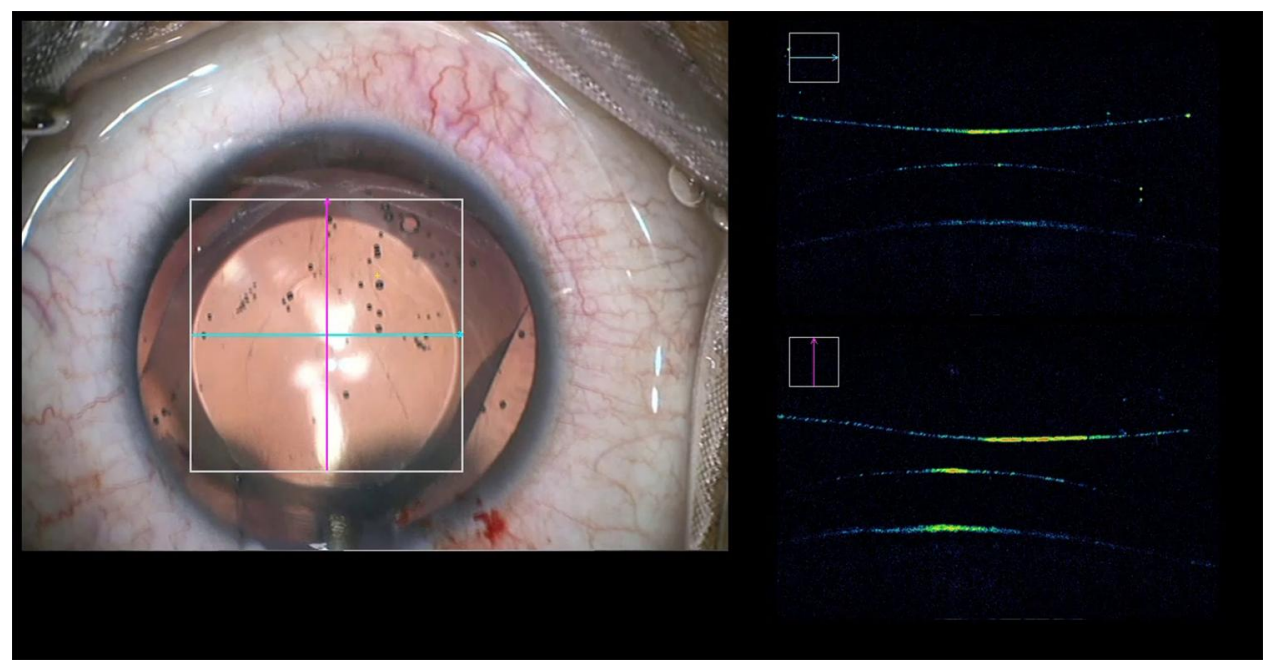

Figure 4 Intraoperatively vaulting and other parameters during phakic IOL surgery can be monitored in real time with iOCT.

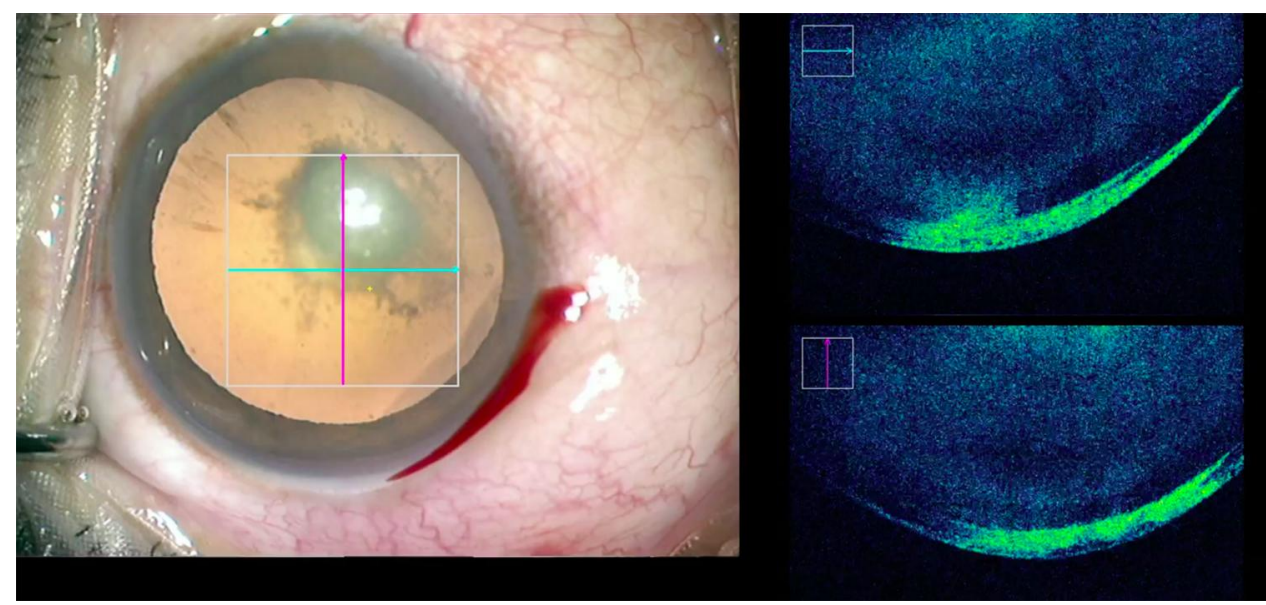

Figure 5 A posterior polar cataract imaged on IOCT prior to initiation of surgery showing an intact posterior capsule.

\section{Corneal and Scleral Needle Track Imaging} The other decisive role of iOCT in ophthalmology is its ability in forecasting the suture paths along various tissues. In an observation assessing the influence of iOCT in trainees surgical skill acquisition, it was noted that it has a crucial role in better judgment of the depth while passing sutures in various anterior segment surgeries. ${ }^{62}$ Depth detailed scleral suture passage, ${ }^{63}$ and volumetric reconstructed $4 \mathrm{D}$ images of muscles while suturing them have been noted in isolation, ${ }^{64}$ but, these concepts need further exploration in a larger and more diverse case scenario (Figures 1 and 6).

\section{Pediatric Eye Diseases}

Retinal evaluation in pediatric patients is a challenging task. Unlike adult patients simple ophthalmoscopic examination takes a certain amount of time, hence, they are often evaluated under some form of anesthesia. During this advantaged time, iOCT is a utilitarian tool to evaluate newborns, infants, and older children with anterior as well as posterior segment pathologies. Using iOCT, corneal anatomy, corneal opacities, sclerocornea, iridocorneal adhesion, anterior chamber details, optic disc findings, foveal contour, and other structural pathologies can be imaged and swift management calls can be taken ${ }^{65-67}$ Similarly, other confounding traumatic conditions involving the retina with systemic morbidities such as the battered baby syndrome and others are imaged on iOCT to localize layer-specific hemorrhages, intra retinal schisis, and foveal irregularities. ${ }^{68-70}$

Retinopathy of prematurity is a clinical entity secondary to interruptions in the well-orchestrated retinal vascular growth. To diagnose, to treat, and to monitor the disease, binocular 


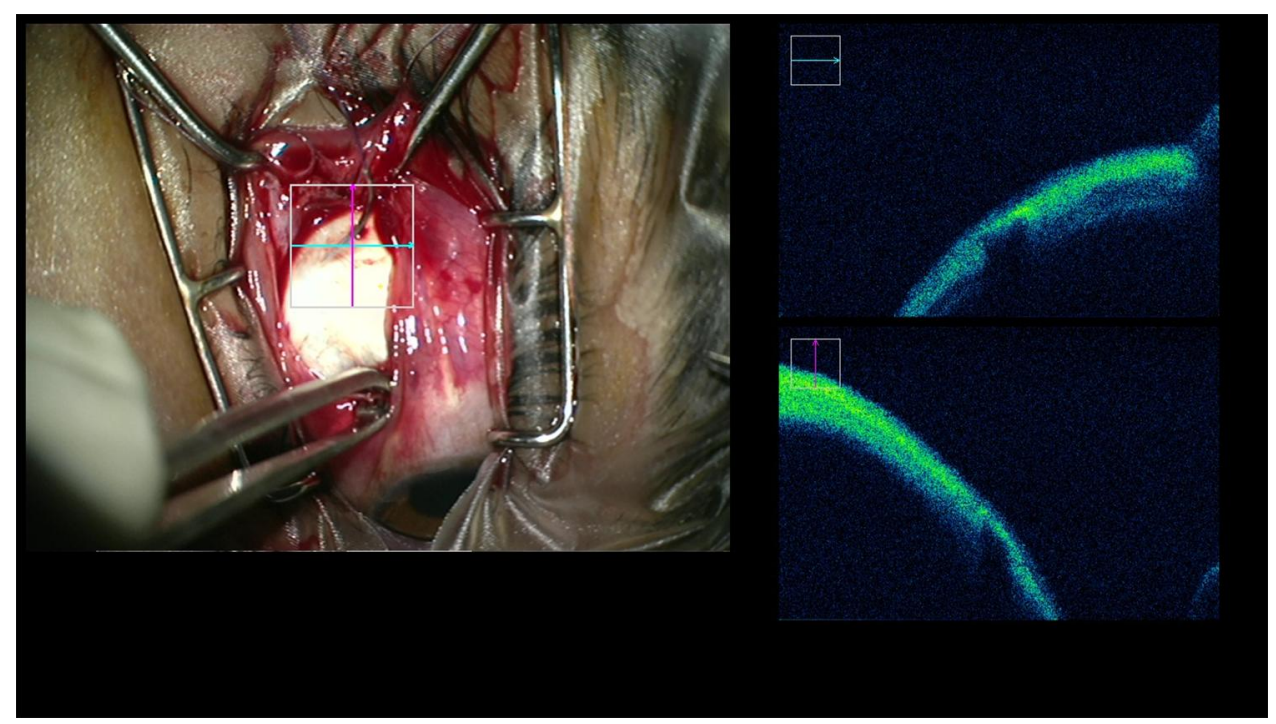

Figure 6 During rectus muscle recession surgery the thin sclera was imaged using iOCT. The approximate thickness guided suture passage helped in preventing scleral complications with real time information.

indirect ophthalmoscopic and Retcam retinal imaging assessment are essential. Nevertheless, subclinical changes which are difficult to be visualized with these routine tools can now be imaged and understood using iOCT. The epiretinal fibrovascular changes, intra-retinal retinoschisis and cystic changes, retinal detachment, tractions, and subretinal changes could be acknowledged for a preemptive clinical care. ${ }^{71-73}$

\section{Retinal Surgery}

The iOCT equally holds an exhaustive role in posterior segment surgeries. Beginning from handheld intraoperative observations till now, evaluation of vital cross-sectional retinal details during/before or after surgical maneuvers have amplified our understandings like never before. The faculty of quick, real time, and dynamic tissue detailing ability, cheers the surgeons with much needed pragmatic judgments at his disposal. Its role in the retina has been elaborated in the following sections.

In adult and older age groups, the heterogeneous group of diseases need intraoperative real time feedback while maneuvering. ${ }^{74,75}$ The applications of iOCT here are segregated into epiretinal, full thickness retinal, and subretinal utilities for better layerwise understandings.

\section{Utility During Epiretinal Maneuvering}

The diseases involving the retinal surface and/or above it are one of the most common indications for surgery in the vitreoretinal category. Vitrectomy, epiretinal membrane peeling, dissection of epiretinal fibrovascular tissues, epiretinal hemorrhage detailing, and others have been shown to have distinctive advantages with the inclusiveness of iOCT. Beginning with vitrectomy, while inducing posterior vitreous separation, preemptive characterization of strong footholds along the retinal surface and optic nerve head were much clearer with iOCT. ${ }^{76,77}$ Intraoperative triamcinolone stained vitreous surgeries are known; however, the visualization of the same using iOCT is new. The injected triamcinolone and indocyanine green were observed to have better discretion ability in the presence of iOCT; in addition, the added 3D reconstruction ability provides delicate information for completion of vitrectomy and prevention of inadvertent peeling of inner retinal layers in pathological conditions (contrast enhanced vitrectomy). ${ }^{78,79}$ Similarly, following the clearing of preretinal hemorrhage and vitreous hemorrhage which often preclude preoperative foveal assessment, can now imaged intraoperatively for delicate foveal understandings. If pathologies are found, then instantaneous decisions can be made on an individual case basis along with en face images and iOCT features. ${ }^{80-82}$ During complex vitrectomy for proliferative diabetic retinopathy, the demonstration of a less traumatic plane for dissection is necessary. The iOCT with its volumetric image reconstruction abilities provides crucial information regarding the plane of dissection in fibrovascular proliferations, subtler tractions, and membranes. ${ }^{83,84}$

The retinal surface is a common interface for the stockpile of various vitreoretinal diseases. The exact cause of superficial layering of the epiretinal membrane (ERM) is less clear, but peeling is commonly intended for various visual benefits. It can be isolated or combined with macular hole surgeries, The usual 
on face surgical view can leave incomplete areas or residual tags at visually significant sites. In recent times, with the introduction of $\mathrm{iOCT}$, it has fascinated most of the clinicians to observe this maneuver to unleash its adjunctive role. ${ }^{85}$ iOCT substitutes in the visualization of cross-sectional details of ERM at a desired site, accurate intraoperative envisioning of its extent, boundaries of peeling, presence of residual tags, and others are possible. Moreover, some of the evidences also emphasize the reduced need for unintended surgical maneuvering with iOCT in the vicinity. ${ }^{74,75,86}$ In an observation by Falkner-Radler et al, ${ }^{87}$ in $40 \%$ of the cases dye was not necessary to peel the ERM, and, in around $95 \%$ of the cases iOCT ascertained its completeness with clear revelations on underlying traumatic changes if at all. ${ }^{88}$ In another observation, $63 \%$ of the eyes were peeled off ERM without the use of dye, ${ }^{89}$ hence, the 4D technology with volumetric information in real time can circumvent the need for dyes as well. ${ }^{25}$ From these cumulative observations iOCT continues to provide new horizons in epiretinal surgeries.

\section{Utility During Full Thickness Retinal Surgery}

This section elaborates the findings observed within the retinal tissue following a surgical maneuver. Macular hole surgery and vitreomacular traction surgery related changes encompass a major portion here.

The larger macular hole surgery involving internal limiting membrane (ILM) peeling following vitrectomy is a special area of interest here. In one observation during the intraoperative period after the ILM peel, a vertical pillar of tissue was evident along edges of the macular hole. The authors speculated that it could represent the residual redundant retinal tissue/ILM tags/epiretinal membrane. This vertical pillar of tissue favored $100 \%$ type I closure of macular holes as compared to the eyes which did not possess such morphology on iOCT. The authors termed this findings as "Hole door sign". 90 The process of inversion of ILM flap into the hole to stuff the defect can be very well configured using iOCT during the entire period of surgery. ${ }^{91,92}$

In some observations it was noted that a change in geometric parameters of macular holes are also possible with ILM peel. An increase in macular hole volume, increase in base area, and increase in subretinal hypo reflectance due to enhanced height between the photoreceptor segments and RPE and changes along the macular hole edges were noted. In addition, dynamic changes along the macular hole edges with mechanical apposition, instant change in base dimensions with soft end instruments were witnessed with real time iOCT. ${ }^{93}$ In addition, tangential tractions, intraretinal cystic changes, foveal contour were also noted very well using iOCT than the on face microscopic view alone. ${ }^{74,75,94,95}$ These changes can be better understood with the added $3 \mathrm{D}$ image reconstruction. ${ }^{96}$

An observation on vitreoretinal surgery on vitreomacular traction (VMT) eyes with iOCT showed a decrease in foveal elevation after severing the traction, however, the sub foveal area showed an increase in hypo reflective space due to exaggerated separation forces between the photoreceptors and RPE. In the same observation, $18 \%$ of the eyes showed conversion from VMT to full thickness macular hole (MH) following traction release and 14\% cases with ILM/ERM related new revelations, thus, the iOCT affected the primary surgical plan in $42 \%$ of the cases $^{97}$ (Figure 7 ).

\section{Subretinal}

Ocular pathologies confined to subretinal space with the need for surgical intervention are customarily complex tasks. The injection along subretinal space can have untoward effects if administered along the sub RPE or intraretinal tissue, ergo needle tip localization and continuous real time monitoring are likely to help in mitigating surgical jerk. iOCT can augment the precision of subretinal injections of tissue plasminogen activators, removal of retained perfluorocarbon liquid droplets and others. ${ }^{98,99}$ And, the added changes along retinal and subretinal tissue can also be visualized on iOCT. ${ }^{100}$ Gregori et al ${ }^{101}$ delivered the viral vectors into subretinal space for gene therapy in hereditary retinal disorders, due to inherently fragile retina and the underlying choroid, inadvertent injection along suprachoroidal space were averted in $60 \%$ of their cases. Thus, iOCT ushered delineation of the retinochoroidal layers in real time can be more desirable in complex scenarios.

\section{Retinal Detachment}

The iOCT, while operating on retinal detachment (RD) eyes has shown the following utilities. During RD surgery, real time subtler intraretinal morphological changes were evidenced which had possible visual implications, that is, the structural changes along IS/OS junction and external limiting membrane following a perfluoro-n-octane infusion and others. ${ }^{102}$ However, the standard RD repair surgery remains the same but efforts can be made using iOCT to correlate the intraoperative morphological details and maneuvering and their effects on postoperative visual outcomes.

The subtler sub foveal changes which are difficult to be visualized on face images can now be delineated on iOCT. Toygar et al $^{103}$ observed the foveal settlement following 


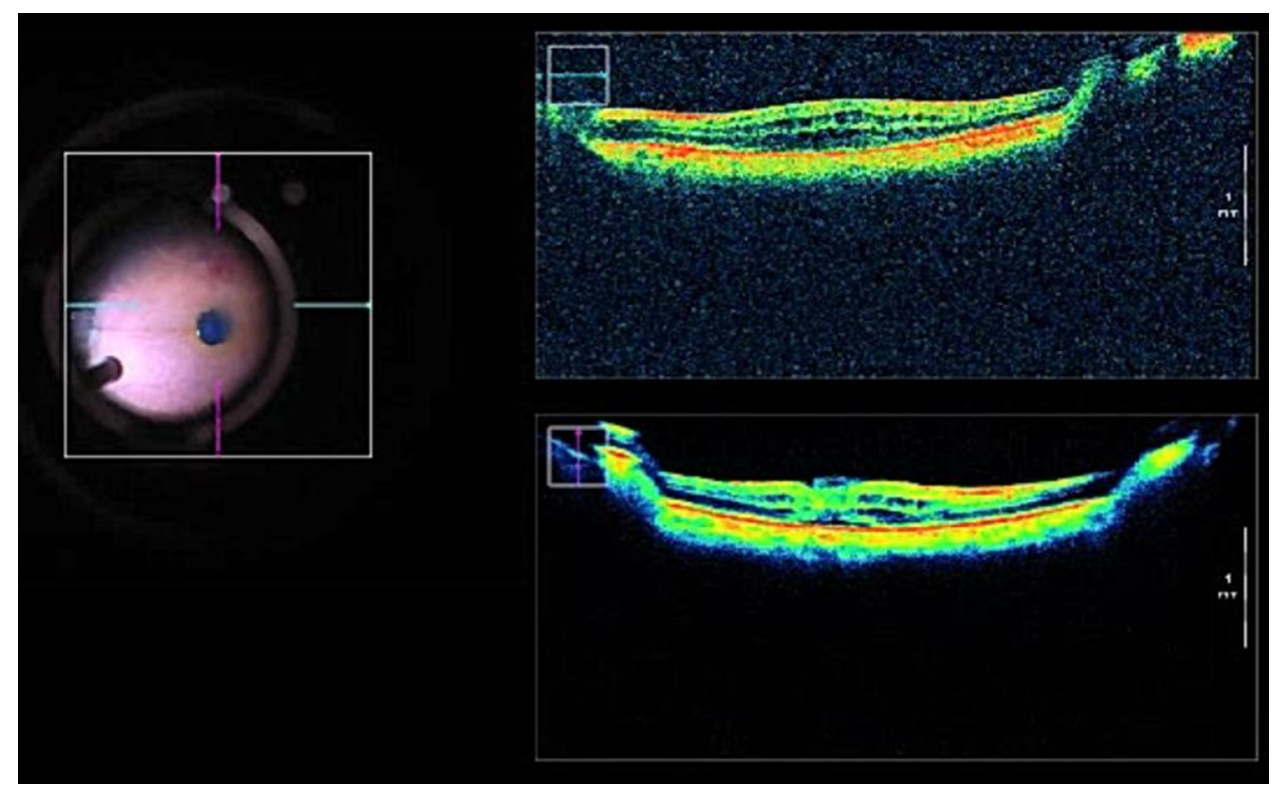

Figure 7 iOCT helped in the visualization of a well-configured ILM flap which is covering the entire defect in a case of large full-thickness macular hole. Intricate details of retinal architecture can also be studied.

injection of perflurons and following air fluid exchange in macula involving retinal detachment surgeries. After the removal of perflurons and following air fluid exchange the subfoveal fluid content was escalated, thus, such customized observations may customize our advices on strict prone positioning in the postoperative period.,

\section{Myopia}

In an observation by Itoh et al, ${ }^{104}$ the iOCT was able to delineate the undisturbed foveal architecture following a foveal sparing ILM peel for myopic retinoschisis. On the contrary, eyes with complete ILM peel witnessed a subclinical foveal detachment. In Kumar et al's ${ }^{105}$ observation while performing center sparing ILM peel for myopic traction maculopathy, the real time images defined the precise location of dynamic tractional forces and enabled their complete removal with a reduced foveal trauma. Similarly, other subtler yet greatly impactable events such as residual fragments of ILM peel, cortical vitreous strands in high myopic eyes, and other grossly invisible foveal changes were also investigated using iOCT $^{106}$ (Figure 8).

\section{Prospective Studies PIONEER Study}

PIONEER stands for Prospective Intraoperative and perioperative Ophthalmic ImagiNg with Optical CoherEncE TomogRaphy. It was a prospective, single center, multi surgeon, consecutive case study intended to uncover the feasibility, utility, and safety of iOCT in ophthalmic surgeries. The 2 years results of 531 eyes involving anterior (275) as well as posterior segment (256) conditions revealed the ability of iOCT in altering the informed decision-making and surgeons' understanding in $48 \%$ of lamellar corneal procedures and $43 \%$ of membrane peeling procedures. DSAEK and vitrectomy followed by membrane peeling were the common procedures observed. The iOCT augmented observations did not show any adverse event, but consumed a total of 4.9 minutes time per scan session. ${ }^{107}$ Similarly, the 2015 PIONEER study again emphasized the influence of iOCT on surgeons while operating on epiretinal membranes, posterior hyaloid tractions, and eyes with dense vitreous hemorrhage. ${ }^{108}$ The other observations gathered from PIONEER studies have been highlighted in the relevant sub-sections also.

\section{DISCOVER Study}

The DISCOVER study stands for Determination of Feasibility of Intraoperative Spectral Domain Microscope Combined/ Integrated OCT Visualization During En Face Retinal and Ophthalmic Surgeries. Again it was a single center, multisurgeon study group exploring the feasibility and utility of iOCT in a large number of anterior and posterior segment entities (837 eyes). The recently published 3 years results show that the iOCT affected the surgeon's intraoperative decision-making ability in $43.4 \%$ of anterior segment surgeries and 


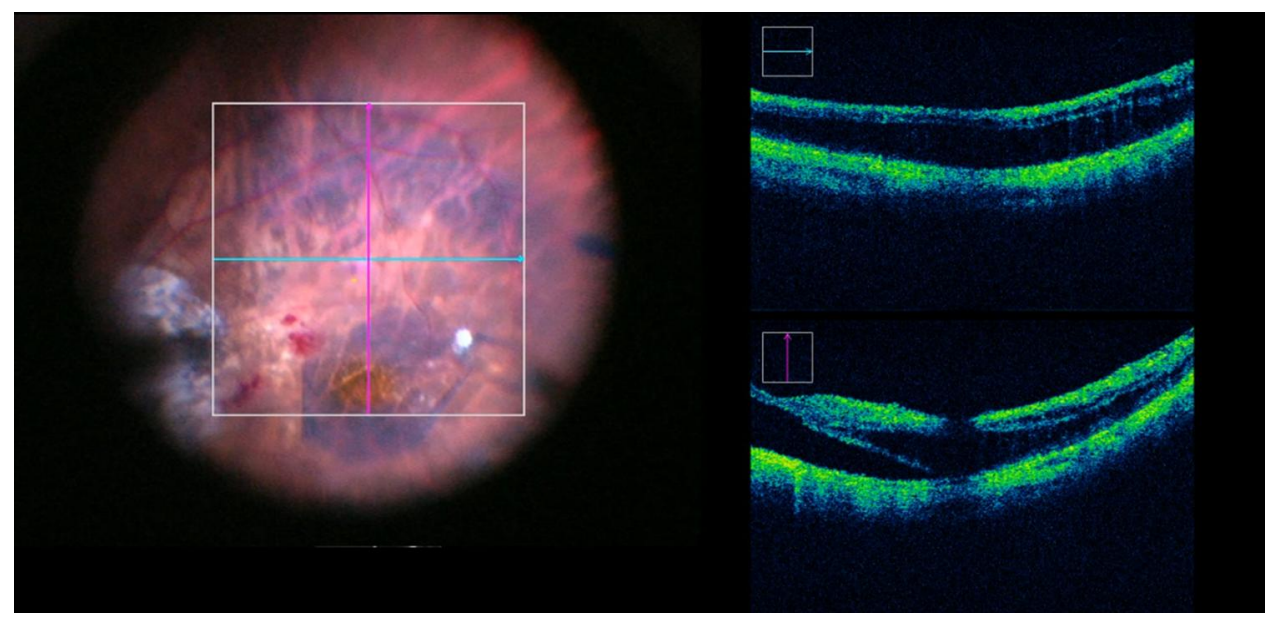

Figure 8 iOCT providing details in detecting the precise location of residual foveal traction and possible occurrence of a full-thickness macular hole if any. This is useful while performing center sparing ILM peeling in cases of myopic traction maculopathy.

in $29.2 \%$ of the posterior segment surgeries. ${ }^{109}$ The study observed the highest number of anterior as well posterior segment diseased patients, and again, in anterior segment surgeries it was mainly comprised of lamellar corneal surgeries, whereas in posterior segment primarily vitrectomy was performed with specified maneuvers for proliferative diabetic retinopathy, epiretinal membrane, macular hole, and others. The other observations of the DISCOVER study group consistently highlights the definitive impact of iOCT on a surgeon's ability to perform surgery based on the real time informations. However, the study has not yet concluded the impact of iOCT on postoperative follow-ups, but proposes the multicenter comparison will further strengthen the consensus on iOCT for future utility. ${ }^{109-111}$

\section{Other Utilities}

While the utilities and newer insights continue to emerge in more common clinical conditions, the ability to image in more complex and challenging scenarios needs constructive exploration. In isolated instances, peripheral retinal imaging for degenerative and pathological changes, ${ }^{112,113}$ assessment of closure of suture less sclerotomy wounds, ${ }^{114}$ and prototypes to image better, wider, and deeper modifications have been narrated. ${ }^{115}$ On the other hand, to refine the technology, customized semitransparent rigid plastic instruments have been experimented on to counter the metallic surgical instrument induced shadowing and other visibility related concerns. ${ }^{116}$ The newer 4D image-guided real time volumetric visualization has enabled the assessment of intraoperative tissueinstrument distance and interaction, volumetric change in the pathological site after intervention, and choroidal mass reconstruction for accurate biopsy. ${ }^{25,117,118}$ Similarly, to make the instrument more compact and negotiable, Mura et $\mathrm{al}^{119}$ described a 23 gauge side scanning SD OCT probe, the endoprobe with tiny dimensions is able to scan the tissue of interest from surface to the subretinal place and from posterior pole to periphery.

\section{Effect on Decision-Making}

As discussed above, the ability of iOCT in influencing the surgeons decision varies. DISCOVER study 3 year results showed an influence of nearly $44 \%$ for anterior segment surgeries and nearly $30 \%$ in posterior segment surgeries. In Pfau et al's ${ }^{120}$ observation decision-making was altered in nearly $42 \%$ of the cases with posterior and combined surgeries but no altered decision was noted in anterior segment surgeries. Similarly, in another observation on vitreoretinal surgeries the decision was affected in slightly more than half of the cases. ${ }^{121}$ Therefore, the effect on decision-making abilities can be more comprehensively addressed, as discussed in the future directions section.

\section{Discussion}

The observations on iOCT have continuously explored, experimented, and defined its key role in various ophthalmic surgeries. $\mathrm{OOCT}$ with its precision in projecting the anatomical details in real time with or without surgical maneuvering has been shown to impact the surgeons decision-making ability.

Previously reviews and expert opinions have also summarized the utility of iOCT in their respective fields. Here 
we discussed the comprehensive role of iOCT in ophthalmic surgeries from a clinician's perspective onto what to expect from iOCT based on existing literature knowledge.

\section{Limitations}

This is a tool for the future, but the good old surgical skills cannot be undermined. Here are some of the major limitations noted throughout the review process.

1) Higher cost and sparse availability makes it a lesser essential tool for a great proportion of ophthalmic surgeons during their routine clinical practice.

2) The iOCT derived observations are in its early phases. Hence, a practical consensus on its exact role in each of the specified surgeries is yet to be understood, and, as of now the iOCT only possesses the adjunctive role from a clinical perspective.

3) Often the studies have included a limited number of patients with subjective conclusions, therefore it limits the extrapolation of its efficacy in a larger subset of patients with less known of multi-centric consensus.

4) By constantly emphasizing iOCT, it inherits the damage to basic surgical and intraoperative judgmental skills during training periods and also for younger surgeons.

\section{Conclusion}

To conclude, the iOCT has enriched our "preliminary understandings" in a diverse group of ophthalmic conditions thus far. Using iOCT intraoperative valuation of specific anatomical, morphological, and depth detailed events in real time is possible in anterior segment, posterior segment, extraocular, and ocular surface surgeries. Therefore, by incorporating this crucial information, our routine surgical exercises and patient outcomes can be enhanced in a comprehensive way. However, the abovementioned limitations hinder our more affirmative and broader conclusions, therefore, by incorporating the below-mentioned directives in future studies, iOCTs role in ophthalmic surgeries can be defined in a more refined way.

\section{Future Directions}

1) As the described utilities of iOCT are single center, limited surgeon, simple case, and/or isolated observations, future studies must be intended to explore the role of iOCT in a multicentric, blinded (if feasible), and more complex case scenarios.
2) A common consensus needs to be derived on to what extent the iOCT driven surgeries will help the surgeon as well as the patient in a given scenario.

3) To image the structures continuously without any interruptions, customized nonmetallic operative tools need clear validation in terms of surgical as well as technical benefits.

4) A real time cross-sectional imaging facility needs to be refined for faster, wider, and deeper scanning. This should be intended to advantage the patients with advanced media opacity thriving for visual rehabilitation.

5) Artificial intelligence driven intraoperative assessment, judgments, and objective directions can make the iOCT a more safe and reliable tool.

\section{Disclosure}

The authors report no conflicts of interest for this work.

\section{References}

1. Huang D, Swanson EA, Lin CP, et al. Optical coherence tomography. Science. 1991;254(5035):1178-1181. doi:10.1126/ science. 1957169

2. Titiyal JS, Kaur M, Falera R. Intraoperative optical coherence tomography in anterior segment surgeries. Indian J Ophthalmol. 2017;65(2):116-121. doi:10.4103/ijo.IJO_868_16

3. Hahn P, Migacz J, O'Connell R, et al. The use of optical coherence tomography in intraoperative ophthalmic imaging. Ophthalmic Surg Lasers Imaging. 2011;42(4):S85-S94. doi:10.3928/15428877-20110627-08

4. Augustin AJ. Intraoperative optical coherence tomography - an overview of current clinical data for the application in the anterior and posterior segments. Klin Monatsbl Augenheilkd. 2018;235 (7):820-829. doi:10.1055/s-0042-122710

5. Khan M, Ehlers JP. Clinical utility of intraoperative optical coherence tomography. Curr Opin Ophthalmol. 2016;27(3):201-209. doi:10.1097/ICU.0000000000000258

6. Ehlers JP. Intraoperative optical coherence tomography: past, present, and future. Eye Lond Engl. 2016;30:193-201.

7. Ehlers JP, Tao YK, Srivastava SK. The value of intraoperative optical coherence tomography imaging in vitreoretinal surgery. Curr Opin Ophthalmol. 2014;25:221-227. doi:10.1097/ ICU.0000000000000044

8. Hüttmann G, Lankenau E, Schulz-Wackerbarth C, et al. Optical coherence tomography: from retina imaging to intraoperative use - a review. Klin Monatsbl Augenheilkd. 2009;226:958-964. doi:10.1055/s-0028-1109939

9. Tao YK, Ehlers JP, Toth CA, et al. Intraoperative spectral domain optical coherence tomography for vitreoretinal surgery. Opt Lett. 2010;35(20):3315-3317. doi:10.1364/OL.35.003315

10. Jayadev C, Dabir S, Shah U, et al. Microscope-integrated optical coherence tomography: a new surgical tool in vitreoretinal surgery. Indian J Ophthalmol. 2015;63(5):399-403. doi:10.4103/ 0301-4738.159865

11. Ung C, Miller JB. Intraoperative optical coherence tomography in vitreoretinal surgery. Semin Ophthalmol. 2019;34(4):4, 312-316. doi:10.1080/08820538.2019.1620811

12. Maier MM, Nasseri A, Framme C, et al. Intraoperative optical coherence tomography in vitreoretinal surgery: clinical experiences and future developments. Klin Monatsbl Augenheilkd. 2018;235(9):1028-1034. doi:10.1055/s-0043-106304 
13. Au J, Goshe J, Dupps WJ, et al. Intraoperative optical coherence tomography for enhanced depth visualization in deep anterior lamellar keratoplasty from the PIONEER Study. Cornea. 2015;34(9):1039-1043. doi:10.1097/ICO.0000000000000508

14. De Benito-llopis L, Mehta JS, Angunawela RI, et al. Intraoperative anterior segment optical coherence tomography: a novel assessment tool during deep anterior lamellar keratoplasty. Am $J$ Ophthalmol. 2014;157(2):334-341.e3. doi:10.1016/j.ajo.2013.10.001

15. Bhullar PK, Carrasco-Zevallos OM, Dandridge A, et al. Intraocular pressure and big bubble diameter in deep anterior lamellar keratoplasty: an ex-vivo microscope-integrated OCT with heads-up display study. Asia Pac J Ophthalmol (Phila). 2017;6:412-417. doi:10.22608/APO.2017265

16. Siebelmann S, Steven P, Cursiefen C. Intraoperative optical coherence tomography in deep anterior lamellar keratoplasty. Klin Monatsbl Augenheilkd. 2016;233:717-721. doi:10.1055/ s-0042-108588

17. Steven P, Le Blanc C, Lankenau E, et al. Optimising deep anterior lamellar keratoplasty (DALK) using intraoperative online optical coherence tomography (iOCT). $B r \quad J$ Ophthalmol. 2014;98 (7):900-904. doi:10.1136/bjophthalmol-2013-304585

18. Liu Y-C, Wittwer VV, Yusoff NZM, et al. Intraoperative optical coherence tomography-guided femtosecond laser-assisted deep anterior lamellar keratoplasty. Cornea. 2019;38:648-653. doi:10.1097/ICO.0000000000001851

19. Zakaria N, Ní Dhubhghaill S, Taal M, et al. Optical coherence tomography in cultivated limbal epithelial stem cell transplantation surgery. Asia Pac J Ophthalmol. 2015;4(6):339-345. doi:10.1097/APO.0000000000000163

20. Siebelmann S, Horstmann J, Scholz $P$, et al. Intraoperative changes in corneal structure during excimer laser phototherapeutic keratectomy (PTK) assessed by intraoperative optical coherence tomography. Graefes Arch Clin Exp Ophthalmol. 2018;256 (3):575-581. doi:10.1007/s00417-017-3867-7

21. Sharma N, Singhal D, Maharana PK, et al. Continuous intraoperative optical coherence tomography-guided shield ulcer debridement with tuck in multilayered amniotic membrane transplantation. Indian $J$ Ophthalmol. 2018;66(6):816-819. doi:10.4103/ijo.IJO_929_17

22. Schmidt EM, Stiefel $\overline{H C}$, Houghton DC, et al. Intraoperative optical coherence tomography to guide corneal biopsy: a case report. Cornea. 2019;38(5):639-641. doi:10.1097/ ICO.0000000000001873

23. Pujari A, Mukhija R, Urkude J, et al. Intraoperative assessment of corneal injuries using microscope-integrated optical coherence tomography. Indian $J$ Ophthalmol. 2018;66(11):1614-1615. doi:10.4103/ijo.IJO_546_18

24. Eguchi H, Kusaka S, Arimura-Koike E, et al. Intraoperative optical coherence tomography (RESCAN ${ }^{\circledR} 700$ ) for detecting iris incarceration and iridocorneal adhesion during keratoplasty. Int Ophthalmol. 2017;37:761-765. doi:10.1007/s10792-016$0322-4$

25. Carrasco-Zevallos OM, Keller B, Viehland C, et al. Live volumetric (4D) visualization and guidance of in vivo human ophthalmic surgery with intraoperative optical coherence tomography. Sci Rep. 2016;19(6):31689. doi:10.1038/srep31689

26. Kobayashi A, Yokogawa H, Mori N, et al. Visualization of precut DSAEK and pre-stripped DMEK donor corneas by intraoperative optical coherence tomography using the RESCAN 700. BMC Ophthalmol. 2016;4(16):135. doi:10.1186/s12886-016-0308-z

27. Hallahan KM, Cost B, Goshe JM, et al. Intraoperative interface fluid dynamics and clinical outcomes for intraoperative optical coherence tomography-assisted descemet stripping automated endothelial keratoplasty from the PIONEER Study. $\mathrm{Am}$ J Ophthalmol. 2017;173:16-22. doi:10.1016/j.ajo.2016.09.028
28. Steverink JG, Wisse RPL. Intraoperative optical coherence tomography in descemet stripping automated endothelial keratoplasty: pilot experiences. Int Ophthalmol. 2017;37(4):939-944. doi:10.1007/s10792-016-0338-9

29. de T, Wang J, Tao A, et al. Intraoperative use of three-dimensional spectral-domain optical coherence tomography. Ophthalmic Surg Lasers Imaging. 2010;41:250-254. doi:10.3928/15428877-20100303-15

30. Titiyal JS, Kaur M, Falera R, et al. Evaluation of time to donor lenticule apposition using intraoperative optical coherence tomography in descemet stripping automated endothelial keratoplasty. Cornea. 2016;35:477-481. doi:10.1097/ICO.0000000000000757

31. Xu D, Dupps WJ, Srivastava SK, et al. Automated volumetric analysis of interface fluid in descemet stripping automated endothelial keratoplasty using intraoperative optical coherence tomography. Invest Ophthalmol Vis Sci. 2014;55:5610-5615. doi:10.1167/iovs.14-14346

32. Pasricha ND, Shieh C, Carrasco-Zevallos OM, et al. Real-time microscope-integrated OCT to improve visualization in DSAEK for advanced bullous keratopathy. Cornea. 2015;34(12):16061610. doi:10.1097/ICO.0000000000000661

33. Shazly TA, To LK, Conner IP, et al. Intraoperative optical coherence tomography-assisted descemet stripping automated endothelial keratoplasty for anterior chamber fibrous ingrowth. Cornea. 2017;36(6):757-758. doi:10.1097/ICO.0000000000001192

34. Sharma N, Sahay P, Maharana PK, et al. Microscope integrated intraoperative optical coherence tomography-guided DMEK in corneas with poor visualization. Clin Ophthalmol. 2020;14:643651. doi:10.2147/OPTH.S230195

35. Saad A, Guilbert E, Grise-Dulac A, Sabatier P, Gatinel D. Intraoperative OCT-assisted DMEK: 14 consecutive cases. Cornea. 2015;34(7):802-807. doi:10.1097/ICO.0000000000000462

36. Patel AS, Goshe JM, Srivastava SK, et al. Intraoperative optical coherence tomography-assisted descemet membrane endothelial keratoplasty in the DISCOVER study: first 100 cases. $\mathrm{Am}$ J Ophthalmol. 2020;210:167-173. doi:10.1016/j.ajo.2019.09.018

37. Steven P, Le Blanc C, Velten K, et al. Optimizing descemet membrane endothelial keratoplasty using intraoperative optical coherence tomography. JAMA Ophthalmol. 2013;131:1135-1142. doi:10.1001/jamaophthalmol.2013.4672

38. Cost B, Goshe JM, Srivastava S, Ehlers JP. Intraoperative optical coherence tomography-assisted descemet membrane endothelial keratoplasty in the DISCOVER study. Am $J$ Ophthalmol. 2015;160(3):430-437. doi:10.1016/j.ajo.2015.05.020

39. Mazzotta C, Caragiuli S. Intraoperative corneal thickness measurement by optical coherence tomography in keratoconic patients undergoing corneal collagen cross-linking. $\mathrm{Am}$ $J \quad$ Ophthalmol. 2014;157(6):1156-1162. doi:10.1016/j. ajo.2014.02.042

40. Chow VWS, Biswas S, Yu M, et al. Intraoperative pachymetry using spectral-domain optical coherence tomography during accelerated corneal collagen crosslinking. Biomed Res Int. 2013;2013:848363.

41. Ghaffari R, Mortazavi M, Anvari P, et al. Intraoperative optical coherence tomography to evaluate the effect of the eyelid speculum on corneal pachymetry during accelerated corneal cross-linking (9 mW/cm2). Eye Lond Engl. 2018;32:579-585.

42. Siebelmann S, Händel A, Matthaei $M$, et al. Microscopeintegrated optical coherence tomography-guided drainage of acute corneal hydrops in keratoconus combined with suturing and gas-aided reattachment of descemet membrane. Cornea. 2019;38(8):1058-1061. doi:10.1097/ICO.0000000000001958

43. Tong CM, Parker JS, Dockery PW, et al. Use of intraoperative anterior segment optical coherence tomography for bowman layer transplantation. Acta Ophthalmol (Copenh). 2019;97(7):e1031e1032. doi:10.1111/aos.14104 
44. Sharma N, Urkude J, Chaniyara M, et al. Microscope-integrated intraoperative optical coherence tomography-guided small-incision lenticule extraction: new surgical technique. $J$ Cataract Refract Surg. 2017;43(10):1245-1250. doi:10.1016/j. jcrs.2017.10.015

45. Urkude J, Titiyal JS, Sharma N. intraoperative optical coherence tomography-guided management of cap-lenticule adhesion during SMILE. $J$ Refract Surg. 2017;33:783-786. doi:10.3928/ 1081597X-20170920-01

46. Tan T-E, Liu Y-C, Jayasinghe LS, et al. Intraoperative optical coherence tomography vault measurement in posterior chamber phakic intraocular lens implantation. J Refract Surg. 2017;33 (4):274-277. doi:10.3928/1081597X-20170111-05

47. Titiyal JS, Kaur M, Sahu S, et al. Real-time assessment of intraoperative vaulting in implantable collamer lens and correlation with postoperative vaulting. Eur J Ophthalmol. 2017;27 (1):21-25. doi:10.5301/ejo.5000818

48. Ye C, Yu M, Jhanji V. Stromal bed thickness measurement during laser in situ keratomileusis using intraoperative optical coherence tomography. Cornea. 2015;34(4):387-391. doi:10.1097/ ICO.0000000000000345

49. Das S, Kummelil MK, Kharbanda V, et al. Microscope integrated intraoperative spectral domain optical coherence tomography for cataract surgery: uses and applications. Curr Eye Res. 2016;41 (5):643-652. doi:10.3109/02713683.2015.1050742

50. Amir-Asgari S, Hirnschall N, Findl O. Using continuous intraoperative optical coherence tomography to classify swirling lens fragments during cataract surgery and to predict their impact on corneal endothelial cell damage. J Cataract Refract Surg. 2016;42 (7):1029-1036. doi:10.1016/j.jcrs.2016.04.029

51. Lytvynchuk LM, Glittenberg CG, Falkner-Radler CI, et al. Evaluation of intraocular lens position during phacoemulsification using intraoperative spectral-domain optical coherence tomography. J Cataract Refract Surg. 2016;42(5):694-702. doi:10.1016/j.jcrs.2016.01.044

52. Hirnschall N, Norrby S, Weber M, et al. Using continuous intraoperative optical coherence tomography measurements of the aphakic eye for intraocular lens power calculation. $\mathrm{Br}$ J Ophthalmol. 2015;99(1):7-10. doi:10.1136/bjophthalmol-2013304731

53. Hirnschall N, Farrokhi S, Amir-Asgari S, et al. Intraoperative optical coherence tomography measurements of aphakic eyes to predict postoperative position of 2 intraocular lens designs. J Cataract Refract Surg. 2018;44(11):1310-1316. doi:10.1016/j. jcrs.2018.07.044

54. Li X, Wei L, Dong X, et al. Microscope-integrated optical coherence tomography for image-aided positioning of glaucoma surgery. J Biomed Opt. 2015;20(07):76001. doi:10.1117/1. JBO.20.7.076001

55. Siebelmann S, Cursiefen C, Lappas A, et al. Intraoperative optical coherence tomography enables noncontact imaging during canaloplasty. J Glaucoma. 2016;25(2):236-238. doi:10.1097/ IJG.0000000000000367

56. Swaminathan SS, Chang TC. Use of intraoperative optical coherence tomography for tube positioning in glaucoma surgery. JAMA Ophthalmol. 2017;135:1438-1439. doi:10.1001/ jamaophthalmol.2017.4431

57. Heindl LM, Siebelmann S, Dietlein T, et al. Future prospects: assessment of intraoperative optical coherence tomography in ab interno glaucoma surgery. Curr Eye Res. 2015;40(12):1288-1291. doi:10.3109/02713683.2014.995311

58. Pasricha ND, Bhullar PK, Shieh C, et al. Four-dimensional microscope- integrated optical coherence tomography to enhance visualization in glaucoma surgeries. Indian $J$ Ophthalmol. 2017;65:57-59. doi:10.4103/ijo.IJO_412_16
59. Kumar RS, Jariwala MU, Venugopal JP, et al. A Pilot Study on feasibility and effectiveness of intraoperative spectral-domain optical coherence tomography in glaucoma procedures. Transl Vis Sci Technol. 2015;4(2):2. doi:10.1167/tvst.4.2.2

60. Junker B, Jordan JF, Framme C, Pielen A. Intraoperative optical coherence tomography and ab interno trabecular meshwork surgery with the trabectome. Clin Ophthalmol. 2017;11:1755-1760. doi:10.2147/OPTH.S145873

61. Tanito M. Optical coherence tomography observation of gonio structures during microhook ab interno trabeculotomy. J Ophthalmol. 2017;2017:1-5. doi:10.1155/2017/6310835

62. Todorich B, Shieh C, DeSouza PJ, et al. Impact of microscope-integrated OCT on ophthalmology resident performance of anterior segment surgical maneuvers in model eyes. Invest Ophthalmol Vis Sci. 2016;57:146-153. doi:10.1167/ iovs.15-18818

63. Pujari A, Sharma P, Phuljhele S, et al. Intraoperative optical coherence tomography-guided scleral suture passage while performing surgery on extraocular muscles. Indian J Ophthalmol. 2018;66:1654-1655. doi:10.4103/ijo.IJO_769_18

64. Pasricha ND, Bhullar PK, Shieh C, et al. Four-dimensional microscope-integrated optical coherence tomography to visualize suture depth in strabismus surgery. $J$ Pediatr Ophthalmol Strabismus. 2017;14(54):e1-e5.

65. Siebelmann S, Hermann M, Dietlein T, et al. Intraoperative optical coherence tomography in children with anterior segment anomalies. Ophthalmology. 2015;122(12):2582-2584. doi:10.1016/j.ophtha.2015.06.004

66. Siebelmann S, Bachmann B, Matthaei M, et al. Microscopeintegrated intraoperative optical coherence tomography in examination of pediatric patients under anesthesia. Ophthalmologe. 2018;115(9):785-792. doi:10.1007/s00347-018-0756-3

67. Siebelmann S, Bachmann B, Lappas A, et al. Intraoperative optical coherence tomography for examination of newborns and infants under general anesthesia. Ophthalmologe. 2016;113 (8):651-655. doi:10.1007/s00347-016-0299-4

68. Muni RH, Kohly RP, Sohn EH. Hand-held spectral domain optical coherence tomography finding in shaken-baby syndrome. Retina. 2010;30(4 Suppl):S45-S50. doi:10.1097/IAE.0b013e3181dc048c

69. Scott AW, Farsiu S, Enyedi LB, et al. Imaging the infant retina with a hand-held spectral-domain optical coherence tomography device. Am J Ophthalmol. 2009;147:364-373 e362. doi:10.1016/j. ajo.2008.08.010

70. Wykoff CC, Berrocal AM, Schefler AC, et al. Intraoperative OCT of a full-thickness macular hole before and after internal limiting membrane peeling. Ophthalmic Surg Lasers Imaging. 2015;40 (1):7-11. doi:10.3928/15428877-20091230-01

71. Chavala SH, Farsiu S, Maldonado R, et al. Insights into advanced retinopathy of prematurity using handheld spectral domain optical coherence tomography imaging. Ophthalmology. 2009;116 (12):2448-2456. doi:10.1016/j.ophtha.2009.06.003

72. Muni RH, Kohly RP, Charonis AC, et al. Retinoschisis detected with handheld spectral-domain optical coherence tomography in neonates with advanced retinopathy of prematurity. Arch Ophthalmol. 2010;128:57-62. doi:10.1001/archophthalmol.2009.361

73. Patel CK. Optical coherence tomography in the management of acute retinopathy of prematurity. $A m \quad J$ Ophthalmol. 2006;141:582-584. doi:10.1016/j.ajo.2005.10.002

74. Binder S, Falkner-Radler CI, Hauger C, et al. Feasibility of intrasurgical spectral-domain optical coherence tomography. Retina. 2011;31 (7):1332-1336. doi:10.1097/IAE.0b013e3182019c18

75. Branchini LA, Gurley K, Duker JS, et al. Use of handheld intraoperative spectral-domain optical coherence tomography in a variety of vitreoretinal diseases. Ophthalmic Surg Lasers Imaging Retina. 2016;47:49-54. doi:10.3928/2325816020151214-07 
76. Ehlers JP, Kernstine K, Farsiu S, et al. Analysis of pars plana vitrectomy for optic pit-related maculopathy with intraoperative optical coherence tomography: a possible connection with the vitreous cavity. Arch Ophthalmol. 2011;129:1483-1486. doi:10.1001/archophthalmol.2011.316

77. Rachitskaya AV, Yuan A, Marino MJ, et al. Intraoperative OCT imaging of the Argus II retinal prosthesis system. Ophthalmic Surg Lasers Imaging Retina. 2016;47:999-1003. doi:10.3928/ 23258160-20161031-03

78. Ehlers JP, McNutt SA, Kaiser PK, et al. Contrast-enhanced intraoperative optical coherence tomography. Br J Ophthalmol. 2013;97 (11):1384-1386. doi:10.1136/bjophthalmol-2012-303048

79. Lytvynchuk LM, Glittenberg CG, Ansari-Shahrezaei S, et al. Intraoperative optical coherence tomography assisted analysis of pars plana vitrectomy for retinal detachment in morning glory syndrome: a case report. BMC Ophthalmol. 2017;17(1):134. doi:10.1186/s12886-017-0533-0

80. Heinrich D, Bohnacker S, Nasseri MA, et al. Intraoperative optical coherence tomography in explorative vitrectomy in patients with vitreous haemorrhage-a case series. Ophthalmol Z Dtsch Ophthalmol Ges. 2019;116:261-266.

81. Kumar V, Chandra P, Kumar A. Intraoperative optical coherence tomography guided removal of premacular hemorrhage in Valsalva retinopathy. Indian J Ophthalmol. 2016;64(7):530-531. doi:10.4103/0301-4738.190151

82. Greven MA, Sanislo S. Intraoperative optical coherence tomography demonstrating macular hole associated with ruptured retinal arterial macroaneurysm. Ophthalmic Surg Lasers Imaging Retina. 2019;50(4):e125-e127. doi:10.3928/23258160-20190401-17

83. Gabr H, Chen X, Zevallos-Carrasco OM, et al. Visualization from intraoperative swept-source microscope-integrated optical coherence tomography in vitrectomy for complications of proliferative diabetic retinopathy. Retina Phila Pa. 2018;38(Suppl 1):S110 S120. doi:10.1097/IAE.0000000000002021

84. Agarwal A, Gupta V. Intraoperative optical coherence tomography and proportional reflux hydrodissection-guided pars plana vitrectomy for complex severe proliferative diabetic retinopathy. Indian $J$ Ophthalmol. 2020;68(1):177-181. doi:10.4103/ijo. IJO_978_19

85. Nam DH, Desouza PJ, Hahn P, et al. Intraoperative spectral domain optical coherence tomography imaging after internal limiting membrane peeling in idiopathic epiretinal membrane with connecting strands. Retina. 2015;35(8):1622-1630. doi:10.1097/ IAE.0000000000000534

86. Ehlers JP, Khan M, Petkovsek D, et al. Outcomes of intraoperative OCT-assisted epiretinal membrane surgery from the PIONEER Study. Ophthalmol Retina. 2018;2(4):263-267. doi:10.1016/j.oret.2017.05.006

87. Falkner-Radler CI, Glittenberg C, Gabriel M, et al. Intrasurgica microscope-integrated spectral domain optical coherence tomography-assisted membrane peeling. Retina. 2015;35 (10):2100-2106. doi:10.1097/IAE.0000000000000596

88. Leisser C, Hackl C, Hirnschall N, et al. Visualizing macular structures during membrane peeling surgery with an intraoperative spectral-domain optical coherence tomography device. Ophthalmic Surg Lasers Imaging Retina. 2016;47(4):328-332. doi:10.3928/23258160-20160324-04

89. Leisser C, Hirnschall N, Palkovits S, et al. Intraoperative optical coherence tomography-guided membrane peeling for surgery of macular pucker: advantages and limitations. Ophthalmol $J$ Int Ophtalmol Int $J$ Ophthalmol $Z$ Augenheilkd. 2019;241:234-240

90. Kumar V, Yadav B. HOLE-DOOR SIGN: a novel intraoperative optical coherence tomography feature predicting macular hole closure. Retina Phila Pa. 2018;38(10):2045-2050. doi:10.1097/ IAE.0000000000001791
91. Borrelli E, Palmieri M, Aharrh-Gnama A, et al. Intraoperative optical coherence tomography in the full-thickness macular hole surgery with internal limiting membrane inverted flap placement. Int Ophthalmol. 2019;39(4):929-934. doi:10.1007/s10792-0180880-8

92. Jenkins TL, Adam MK, Hsu J. Intraoperative optical coherence tomography of internal limiting membrane flap. Ophthalmology. 2017;124(10):1456. doi:10.1016/j.ophtha.2017.04.002

93. Ehlers JP, $\mathrm{Xu} \mathrm{D,} \mathrm{Kaiser} \mathrm{PK,} \mathrm{et} \mathrm{al.} \mathrm{Intrasurgical} \mathrm{dynamics} \mathrm{of}$ macular hole surgery: an assessment of surgery-induced ultrastructural alterations with intraoperative optical coherence tomography. Retina. 2014;34(2):213-221. doi:10.1097/ IAE.0b013e318297daf3

94. Dayani PN, Maldonado R, Farsiu S, et al. Intraoperative use of handheld spectral domain optical coherence tomography imaging in macular surgery. Retina. 2009;29(10):1457-1468. doi:10.1097/ IAE.0b013e3181b266bc

95. Ray R, Baranano DE, Fortun JA, et al. Intraoperative microscope-mounted spectral domain optical coherence tomography for evaluation of retinal anatomy during macular surgery. Ophthalmology. 2011;118(11):2212-2217. doi:10.1016/j. ophtha.2011.04.012

96. Lytvynchuk LM, Falkner-Radler CI, Krepler K, et al. Dynamic intraoperative optical coherence tomography for inverted internal limiting membrane flap technique in large macular hole surgery. Graefes Arch Clin Exp Ophthalmol. 2018;38(8):2045-2050. doi:10.1007/s00417-019-04364-5

97. Ehlers JP, Tam T, Kaiser PK, et al. Utility of intraoperative optical coherence tomography during vitrectomy surgery for vitreomacular traction syndrome. Retina. 2014;34(7):1341-1346. doi:10.1097/IAE.0000000000000123

98. Ehlers JP, Petkovsek DS, Yuan A, et al. Intrasurgical assessment of subretinal tPA injection for submacular hemorrhage in the PIONEER study utilizing intraoperative OCT. Ophthalmic Surg Lasers Imaging Retina. 2015;46:327-332. doi:10.3928/ 23258160-20150323-05

99. Smith AG, Cost BM, Ehlers JP. Intraoperative OCT-assisted subretinal perfluorocarbon liquid removal in the DISCOVER study. Ophthalmic Surg Lasers Imaging Retina. 2015;46(9):964-966. doi:10.3928/23258160-20151008-10

100. Lee LB, Srivastava SK. Intraoperative spectral-domain optical coherence tomography during complex retinal detachment repair. Ophthalmic Surg Lasers Imaging. 2011;42 Online (Online):e71-74. doi:10.3928/15428877-20110804-05

101. Gregori NZ, Lam BL, Davis JL. Intraoperative use of microscope-integrated optical coherence tomography for subretinal gene therapy delivery. Retina. 2017. doi:10.1097/ IAE.0000000000001646

102. Junker B, Maier M, Agostini H, et al. Intraoperative optical coherence tomography in retinal detachment. Ophthalmol Z Dtsch Ophthalmol Ges. 2016;113:663-667.

103. Toygar O, Riemann CD. Intraoperative optical coherence tomography in macula involving rhegmatogenous retinal detachment repair with pars plana vitrectomy and perfluoron. Eye Lond Engl. 2016;30:23-30.

104. Itoh Y, Inoue M, Kato Y, et al. Alterations of foveal architecture during vitrectomy for myopic retinoschisis identified by intraoperative optical coherence tomography. Ophthalmol $J$ Int Ophtalmol Int $J$ Ophthalmol $Z$ Augenheilkd. 2019;242:87-97.

105. Kumar A, Ravani R, Mehta A, et al. Outcomes of microscope-integrated intraoperative optical coherence tomography-guided center-sparing internal limiting membrane peeling for myopic traction maculopathy: a novel technique. Int Ophthalmol. 2018;38(4):1689-1696. doi:10.1007/s10792017-0644-x 
106. Bruyère E, Philippakis E, Dupas B, et al. Benefit of intraoperative optical coherence tomography for vitreomacular surgery in highly myopic eyes. Retina Phila Pa. 2018;38(10):2035-2044. doi:10.1097/IAE.0000000000001827

107. Ehlers JP, Dupps WJ, Kaiser PK, et al. The prospective intraoperative and perioperative ophthalmic imaging with optical coherence tomography (PIONEER) study: 2-year results. $\mathrm{Am}$ $J \quad$ Ophthalmol. 2014;158(5):999-1007. doi:10.1016/j. ajo.2014.07.034

108. Ehlers JP, Griffith JF, Srivastava SK. Intraoperative optical coherence tomography during vitreoretinal surgery for dense vitreous hemorrhage in the pioneer study. Retina Phila Pa. 2015;35 (12):2537-2542. doi:10.1097/IAE.0000000000000660

109. Ehlers JP, Modi YS, Pecen PE, et al. The DISCOVER study 3-year results: feasibility and usefulness of microscope-integrated intraoperative OCT during ophthalmic surgery. Ophthalmology. 2018;125(7):1014-1027. doi:10.1016/j. ophtha.2017.12.037

110. Runkle A, Srivastava SK, Ehlers JP. Microscope-integrated OCT feasibility and utility with the EnFocus system in the DISCOVER study. Ophthalmic Surg Lasers Imaging Retina. 2017;48 (3):216-222. doi:10.3928/23258160-20170301-04

111. Ehlers JP, Goshe J, Dupps WJ, et al. Determination of feasibility and utility of microscope-integrated optical coherence tomography during ophthalmic surgery: the DISCOVER study RESCAN results. JAMA Ophthalmol. 2015;133:1124-1132. doi:10.1001/ jamaophthalmol.2015.2376

112. Nishitsuka $\mathrm{K}$, Nishi $\mathrm{K}$, Namba $\mathrm{H}$, et al. Intraoperative optical coherence tomography imaging of the peripheral vitreous and retina. Retina Phila Pa. 2018;38(3):e20-e22. doi:10.1097/ IAE.0000000000001979

113. Sundar D, Kumar A, Chawla R, et al. Microscope-integrated optical coherence tomography-aided intraoperative diagnosis and management of peripheral tractional retinoschisis. Indian $J \quad$ Ophthalmol. 2018;66(9):1323-1324. doi:10.4103/ijo. IJO_331_18
114. Jusufbegovic D, Ozkok A, Schaal S. Intraoperative optical coherence tomography validates the immediate efficacy of external diathermy in sealing 25-gauge sclerotomy wounds. Retina Phila Pa. 2017;37(2):402-404. doi:10.1097/IAE.0000000000001278

115. Lu CD, Waheed NK, Witkin A, et al. Microscope-integrated intraoperative ultrahigh-speed swept-source optical coherence tomography for widefield retinal and anterior segment imaging. Ophthalmic Surg Lasers Imaging Retina. 2018;49(2):94-102. doi:10.3928/23258160-20180129-03

116. Ehlers JP, Uchida A, Srivastava SK. Intraoperative optical coherence tomography-compatible surgical instruments for real-time image-guided ophthalmic surgery. Br J Ophthalmol. 2017;101 (10):1306-1308. doi:10.1136/bjophthalmol-2017-310530

117. Carrasco-Zevallos OM, Keller B, Viehland C, et al. Optical coherence tomography for retinal surgery: perioperative analysis to real-time four-dimensional image-guided surgery. Invest Ophthalmol Vis Sci. 2016;57(9):OCT37-OCT50. doi:10.1167/ iovs.16-19277

118. Grewal DS, Bhullar PK, Pasricha ND, et al. Intraoperative 4-dimensional microscope-integrated optical coherence tomography-guided 27-gauge transvitreal choroidal biopsy for choroidal melanoma. Retina Phila Pa. 2017;37:796-799. doi:10.1097/IAE.0000000000001326

119. Mura M, Barca F. Intraocular optical coherence tomography. Dev Ophthalmol. 2014;54:147-149.

120. Pfau M, Michels S, Binder S, et al. Clinical experience with the first commercially available intraoperative optical coherence tomography system. Ophthalmic Surg Lasers Imaging Retina. 2015;46(10):1001-1008. doi:10.3928/23258160-20151027-03

121. Ramírez-Estudillo JA, Sánchez-Ramos JA, Pérez-Montaño CR, et al. Intraoperative use of coherence tomography in vitreoretinal surgery. Cir Cir. 2017;85(1):21-26. doi:10.1016/j. circir.2016.04.002
Clinical Ophthalmology

\section{Publish your work in this journal}

Clinical Ophthalmology is an international, peer-reviewed journal covering all subspecialties within ophthalmology. Key topics include: Optometry; Visual science; Pharmacology and drug therapy in eye diseases; Basic Sciences; Primary and Secondary eye care; Patient Safety and Quality of Care Improvements. This journal is indexed on PubMed

\section{Dovepress}

Central and CAS, and is the official journal of The Society of Clinical Ophthalmology (SCO). The manuscript management system is completely online and includes a very quick and fair peer-review system, which is all easy to use. Visit http://www.dovepress.com/ testimonials.php to read real quotes from published authors. 